\title{
Prevalence, indications, and outcomes of caesarean section deliveries in Ethiopia: a systematic review and meta-analysis
}

Getnet Gedefaw ${ }^{1 *}$, Asmamaw Demis ${ }^{2}$, Birhan Alemnew ${ }^{3}$, Adam Wondmieneh $^{2}$, Addisu Getie ${ }^{2}$ and Fikadu Waltengus ${ }^{4}$

\begin{abstract}
Background: Caesarean section rates have increased worldwide in recent decades. Caesarean section is an essential maternal healthcare service. However, it has both maternal and neonatal adverse outcomes. Therefore this systematic review and meta-analysis aimed to estimate the prevalence, indication, and outcomes of caesarean section in Ethiopia.

Methods: Twenty three cross-sectional studies with a total population of 36,705 were included. Online databases (PubMed/Medline, Hinari, Web of Science, and Google Scholar) and online university repository was used. All the included papers were extracted and appraised using the standard extraction sheet format and Joanna Briggs Institute respectively. The pooled prevalence of the caesarean section, indications, and outcomes was calculated using the random-effect model.

Result: The overall pooled prevalence of Caesarean section was 29.55\% (95\% Cl: 25.46-33.65). Caesarean section is associated with both maternal and neonatal complications. Cephalopelvic disproportion [18.13\%(95\%Cl: $12.72-$ 23.53] was the most common indication of Caesarean section followed by non-reassuring fetal heart rate pattern [19.57\% (95\%Cl: 16.06-23.08]. The common neonatal complications following Caesarean section included low APGAR score, perinatal asphyxia, neonatal sepsis, meconium aspiration syndrome, early neonatal death, stillbirth, and prematurity whereas febrile morbidity, surgical site infection, maternal mortality, severe anemia, and postpartum hemorrhage were the most common maternal complications following Caesarean section.

Conclusion: In this systematic review and meta-analysis, the rate of Cesarean section was high. Cephalopelvic disproportion, low Apgar score, and febrile morbidity were the most common indication of Caesarean section, neonatal outcome and maternal morbidity following Caesarean section respectively. Increasing unjustified Caesarean section deliveries as a way to increase different neonatal and maternal complications, then several interventions needed to target both the education of professionals and the public.
\end{abstract}

Keywords: Caesarean section, Maternal complications, Meta-analysis, Neonatal complications

\footnotetext{
* Correspondence: gedefawget@gmail.com

'Department of Midwifery, College of Health Sciences, Woldia University, P.O.Box:400, Woldia, Ethiopia

Full list of author information is available at the end of the article
}

(C) The Author(s). 2020 Open Access This article is licensed under a Creative Commons Attribution 4.0 International License, which permits use, sharing, adaptation, distribution and reproduction in any medium or format, as long as you give appropriate credit to the original author(s) and the source, provide a link to the Creative Commons licence, and indicate if changes were made. The images or other third party material in this article are included in the article's Creative Commons licence, unless indicated otherwise in a credit line to the material. If material is not included in the article's Creative Commons licence and your intended use is not permitted by statutory regulation or exceeds the permitted use, you will need to obtain permission directly from the copyright holder. To view a copy of this licence, visit http://creativecommons.org/licenses/by/4.0/ The Creative Commons Public Domain Dedication waiver (http://creativecommons.org/publicdomain/zero/1.0/) applies to the data made available in this article, unless otherwise stated in a credit line to the data. 


\section{Background}

Caesarean section is the commonest operative delivery technique in the world. Caesarean section is the delivery of the fetus, membrane, and placenta through abdominal and uterine incision after fetal viability [1].

The rate of Caesarean section is different across countries even between urban and rural areas, due to different socio-economic statuses, and opportunities to access public and private health care services [2].

According to American College of Obstetricians and Gynecologist (ACOG) report, Caesarean delivery significantly increased woman's risk vulnerability of pregnancyrelated morbidity and mortality which accounts (35.9 deaths per 100,000 live deliveries) as compared to a women posses vaginal delivery (9.2 deaths per 100,000 live births) [3].

Despite Caesarean section a life saving medical intervention and procedures to the decrease adverse birth outcome, controlling different postoperative neonatal and maternal complications are challenging in terms of patient safety, long duration of hospital stay, cost and psychological trauma. Maternal outcomes of Caesarean section included: postpartum fever, surgical site infection, puerperal sepsis, maternal mortality whereas neonatal sepsis, early neonatal death, stillbirth, perinatal asphyxia, low Apgar score, and prematurity were the most common complication of the newborn [4-6].

Despite World Health Organization (WHO) recommended the optimal rate of Caesarean section should be lie between 5 and 15\%, it is significantly increasing even if the reasons for the continued increase in the Caesarean rates are not completely understood: women are having fewer children, maternal age is rising, use of electronic fetal monitoring is widespread, malpresentation especially breech presentation, frequency of forceps and vacuum delivery is decreased, rate of labor induction increases, obesity dramatically rises and Vaginal birth after Caesarean decreased are some of the possible explanations [7].

Previous Caesarean scar, malpresentation and malposition, antepartum hemorrhage, obstructed labor, cephalopelvic disproportion, non-reassuring fetal heart rate pattern, and multiple pregnancies are the most common indications of Caesarean section [4-6, 8].

According to the 2016 Ethiopia Demographic and Health Survey, the rate of C-section (21.4\%) in Addis Ababa was far more than the $10-15 \%$ rate recommended by the world health organization. EDHS (2016) report showed there is an absolute difference rate of Caesarean section across different regions in Ethiopia which accounts Amhara (2.3\%), Oromia (0.9\%), SNNPR(1.9\%), Afar (0.7\%), Tigray (2\%), Somali(0.4\%), Benishangul Gumuz (1\%) too far from the lowest $5 \%$ WHO recommendation of Caesarean section deliveries.
This review helps to see C-section rates beyond $15 \%$ and below $5 \%$ is considered medically unjustified or unnecessary, with negligible benefits for most mothers, and yet costly and unequally distributed throughout the population $[9,10]$.

Ethiopia is a good case study to assess Caesarean prevalence, indications, and outcomes because, like other countries in sub-Saharan Africa, maternal mortality and neonatal mortality did not decline sufficiently to meet the Sustainable Development Goal for maternal health and child, and was estimated at 412 maternal deaths and 29 neonatal deaths per 100,000 live births in 2016 [9].

Despite a few single studies stated different maternal and fetal outcomes of Caesarean section, there is a lack of data to show the distribution and outcome of Caesarean section in different regions where they are provided.

This systematic review and meta-analysis aimed to estimate the pooled prevalence of Caesarean section deliveries and to determine the indications and outcomes of Caesarean section deliveries in Ethiopia.

\section{Methods}

This systematic review and meta-analysis have been conducted to estimate the pooled prevalence of Caesarean section, indications, maternal and neonatal outcomes in Ethiopia via the standard PRISMA checklist guideline.

\section{Search strategy}

International databases (PubMed, Google Scholar, Web of science and HINARI), different gray works of literature and articles in the university repository were included. The searching engine terms were used using PICO formulating questions. These are: "newborn", "neonatal", "birth outcome", "stillbirth", perinatal asphyxia"”, "neonatal sepsis", "prematurity”, "early neonatal death", "low Apgar score", "preterm”, "maternal mortality", "wound infection", "surgical site infection", "febrile morbidity"," puerperal sepsis", "puerperal fever", postpartum hemorrhage", "blood loss", "anemia", "leading factors of Caesarean section", "indications of Caesarean section", "Ethiopia". The following search engine terms were used: neonate OR newborn OR women OR infant OR fetal OR children AND "neonatal sepsis" OR "perinatal asphyxia" OR "low Apgar score" OR "stillbirth" OR "prematurity" OR "preterm birth" OR "early neonatal death" OR "perinatal" OR "neonatal death" OR "preterm "puerperal sepsis" OR "puerperal fever" OR "wound infection" OR "surgical site infection" OR "postpartum hemorrhage" OR "anemia" OR "maternal mortality" OR "maternal death" OR "blood loss" OR "indication of Caesarean section, "factors of Caesarean section", "leading factors of Caesarean section", "fetal indication of CS", "Maternal indication of CS"AND Ethiopia and related terms. 


\section{Inclusion and exclusion criteria}

Twenty three (23) cross-sectional studies were included. Articles reported prevalence or/and an indication, or/ and neonatal outcomes or/and maternal outcomes were incorporated. Only English language literature and research articles were included. Studies published till October 2019 were reviewed, screened and appraised for this study. Whereas, articles without full abstracts or texts and articles reported out of the scope of the outcome interest were excluded.

\section{Quality assessment}

GG, AD \& AW independently evaluated the quality of each study using the Joanna Briggs Institute (JBI) quality appraisal checklist [11]. Any disagreement was resolved by the hindrance of the third reviewer (FW, BA \&AG). The following JBI items used to appraise cross-sectional studies were: [1] inclusion criteria, [2] description of study subject and setting, [3] valid and reliable measurement of exposure, [7] objective and standard criteria used, [9] identification of confounder, [10] strategies to handle confounder, [12] outcome measurement, and
[13] appropriate statistical analysis. Hence, studies considered with the JBI checklist value of $50 \%$ and above of the quality assessment indicators as low risk and good to be included for the analysis.

\section{Data extraction}

All the datasets are exported to Endnote version X8 software, and then we transferred to the Microsoft Excel spreadsheet to remove duplicate data in the review. Three authors (GG, AD, and AG) independently extracted all the important data using a standardized JBI data extraction format. Any disagreement between reviewers was resolved by the second team reviewers (FW, BA \& AW). The consensus was declared through critical discussion and evaluation of the articles by the independent group reviewers. The name of the author, sample size, publication year, study area, response rate, region, study design, the prevalence of specific maternal outcomes, the prevalence of neonatal outcomes, indications of Caesarean section, and prevalence of Caesarean section with $95 \% \mathrm{CI}$ were extracted.

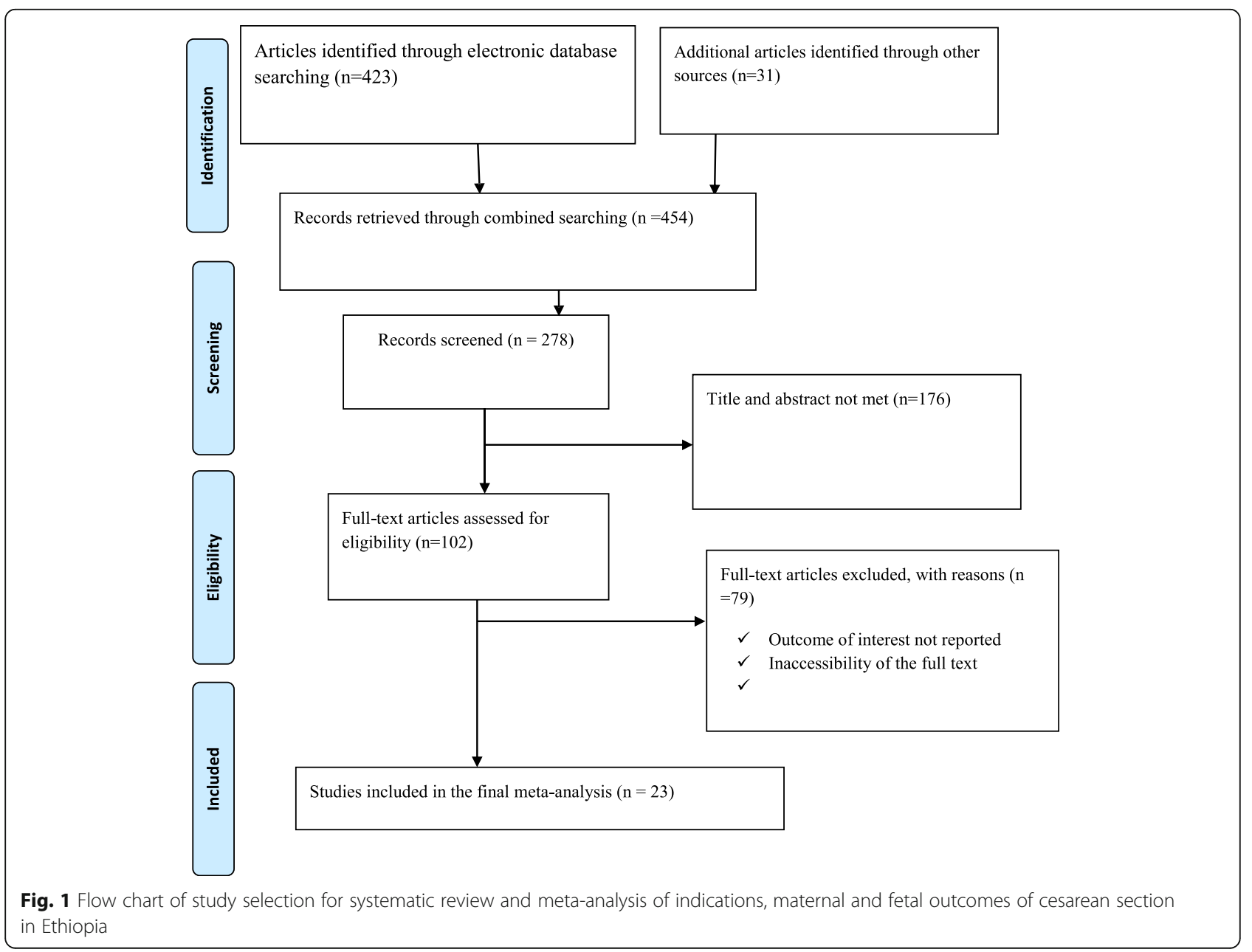


Table 1 Study characteristics included in the systematic review and meta-analysis

\begin{tabular}{|c|c|c|c|c|c|c|c|}
\hline Authors & Region & Study area & Study design & Sample size & Prevalence & Response rate & Quality \\
\hline Jebessa S et al. [12] & SNNPR & Attat & cross-sectional & 3722 & 30.494 & $100 \%$ & Low risk \\
\hline Bizuneh A, Ayana G [13] & SNNPR & Addis Ababa & cross-sectional & 2345 & 24.819 & $100 \%$ & Low risk \\
\hline Amanuel G et al. [18] & Tigray & Mekelle & cross-sectional & 9348 & 31.14 & 100 & Low risk \\
\hline Tesfaye T et al. [19] & SNNPR & Sidama & cross-sectional & 469 & NA & 100 & Low risk \\
\hline Tenaw Z, et al. [20] & SNNPR & Hawassa & cross-sectional & 300 & 49.333 & 98.7 & Low risk \\
\hline Abayneh A [21] & Amhara & Gondar & cross-sectional & 323 & 29.721 & 100 & Low risk \\
\hline Almaz H et al. [22] & SNNPR & Hawassa & cross-sectional & 3195 & 17.089 & 100 & Low risk \\
\hline Ayodeji O et al. [23] & Addis Ababa & Addis Ababa & cross-sectional & 411 & 63.747 & 100 & Low risk \\
\hline Hordofa G, Ashenafi S [24] & SNNPR & Mizan Aaman & cross-sectional & 342 & 21.053 & 100 & Low risk \\
\hline Melaku K et al. [25] & Amhara & Finote selam & cross-sectional & 2267 & 11.028 & 100 & Low risk \\
\hline Bago BJ et al. [26] & Hawassa & Hawassa & cross-sectional & 422 & 35.071 & 98 & Low risk \\
\hline Abebe et al. [27] & Amhara & Bahirdar & cross-sectional & 2967 & 24.368 & 100 & Low risk \\
\hline Hiwot et al. [28] & Addis Ababa & Addis Ababa & cross-sectional & 298 & 38.255 & 100 & Low risk \\
\hline Alemayeu et al. [29] & Harar & Harar & cross-sectional & 422 & NA & 100 & Low risk \\
\hline Bayou YT et al. [30] & Addis Ababa & Addis Ababa & cross-sectional & 835 & 19.281 & 100 & Low risk \\
\hline Wondie et al. [31] & Amhara & Dessie & cross-sectional & 512 & 47.656 & 98.4 & Low risk \\
\hline Tsega et al. [32] & Harar & Harar & cross-sectional & 601 & 34.276 & 95.4 & Low risk \\
\hline Geremew et al. [33] & SNNPR & Attat & cross-sectional & 5611 & 27.571 & 100 & Low risk \\
\hline Solomon et al. [34] & Oromia & Chiro & cross-sectional & 407 & 18.182 & 100 & Low risk \\
\hline Taye and Yuya [35] & Oromia & Jimma & cross-sectional & 388 & 28.351 & 100 & Low risk \\
\hline Mengesha et al [36] & Tigray & Mekelle & cross-sectional & 338 & NA & 100 & Low risk \\
\hline Gebre S, et al. [37] & Tigray & Dansha & cross-sectional & 749 & 13.218 & 100 & Low risk \\
\hline Melese et al. [38] & Amhara & Woldia & cross-sectional & 433 & 30.947 & 100 & Low risk \\
\hline
\end{tabular}

\section{Outcome of measurements}

\section{Neonatal outcomes}

Any neonatal outcomes reported following C-section (Stillbirth, prematurity, neonatal sepsis, perinatal asphyxia, low Apgar score, and early neonatal death) were included.

\section{Maternal outcomes}

Any maternal complications identified after C-section were included puerperal sepsis, wound infection (surgical site infection), febrile morbidity (puerperal fever), postpartum hemorrhage, severe anemia, and maternal mortality.

\section{Indications of caesarean section}

Both maternal and fetal indications (obstructed labor, cephalo pelvic disproportion, NRFHRP (Non-reassuring fetal heart rate pattern), multiple gestations, failed induction, malpresentation, malposition, and antepartum hemorrhage) were included.

\section{Data analysis}

A Funnel plot and Eggers regression test was used to check publication bias [14]. Cochrane Q-test and Isquared statistics were computed to check the heterogeneity of studies $[15,16]$. Pooled analysis was conducted using a weighted inverse variance randomeffects model [17]. Subgroup analysis was done by study region (area), and sample size. STATA version 11 statistical software was used to compute the analysis. Forest plot format was used to present the pooled point prevalence, indications and outcomes of C-section with $95 \% \mathrm{Cl}$.

\section{Results}

\section{Characteristics of the included studies}

Four hundred twenty-three studies were retrieved at PubMed, Google Scholar, Science Direct, web of science, HINARI and other gray and online repository accessed articles regarding prevalence, indications, and the maternal and fetal outcome of Caesarean section in Ethiopia. After duplicates were expunged, 278 studies remained.

Out of 278 remained articles, 176 articles were excluded after review of their titles and abstracts. Therefore, 102 full-text articles were accessed and assessed for inclusion criteria, which resulted in the further exclusion of 79 articles primarily due to reason. As a result, 23 studies were met the inclusion criteria to undergo the final systematic review and meta-analysis (Fig. 1) (Table 1). 


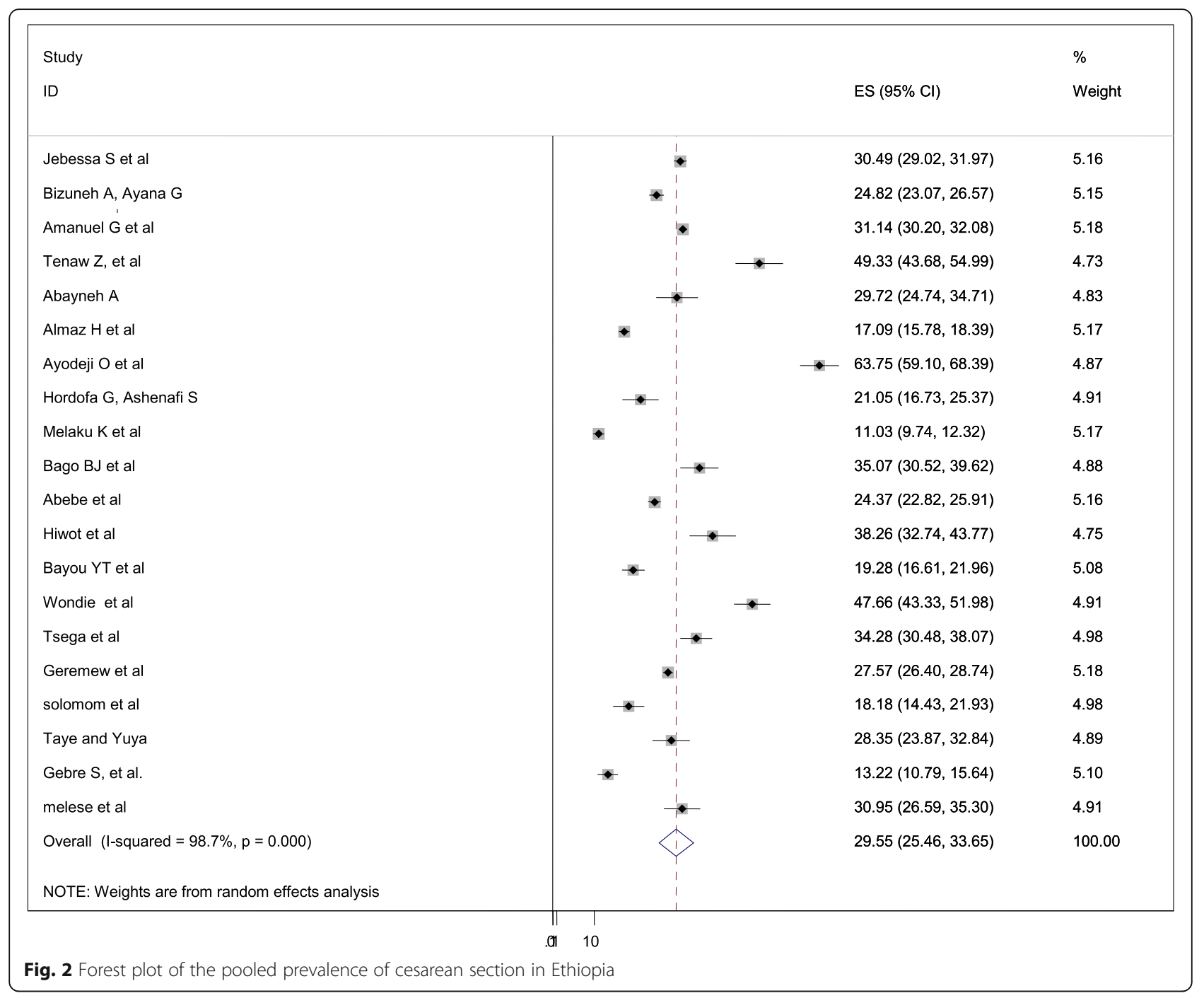

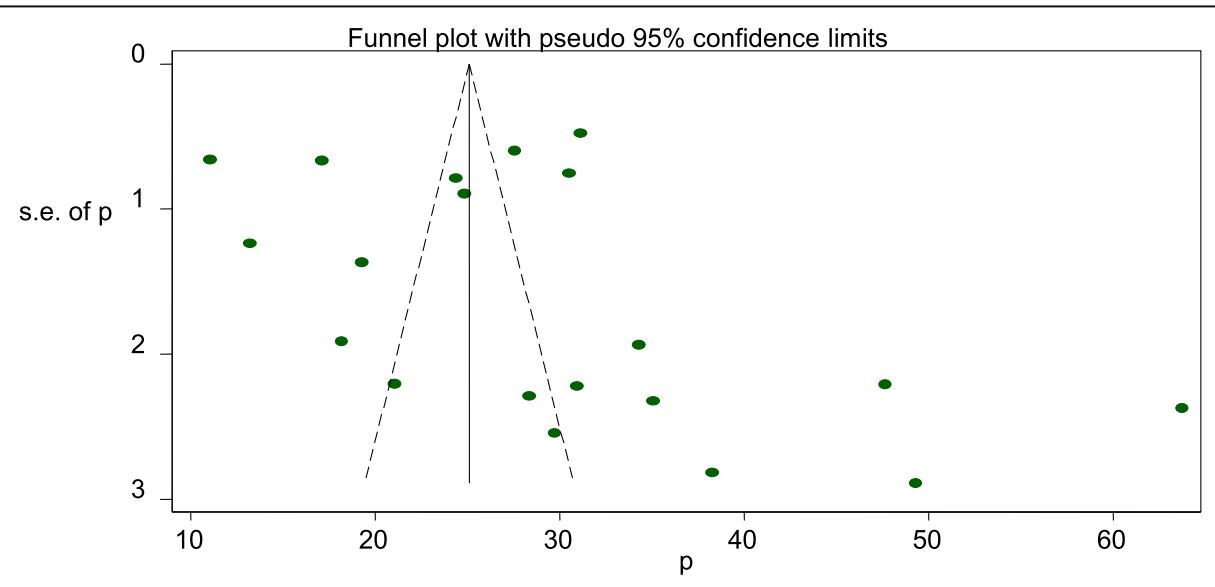

Fig. 3 Funnel plot with 95\% confidence limits of the pooled prevalence of cesarean section in Ethiopia 


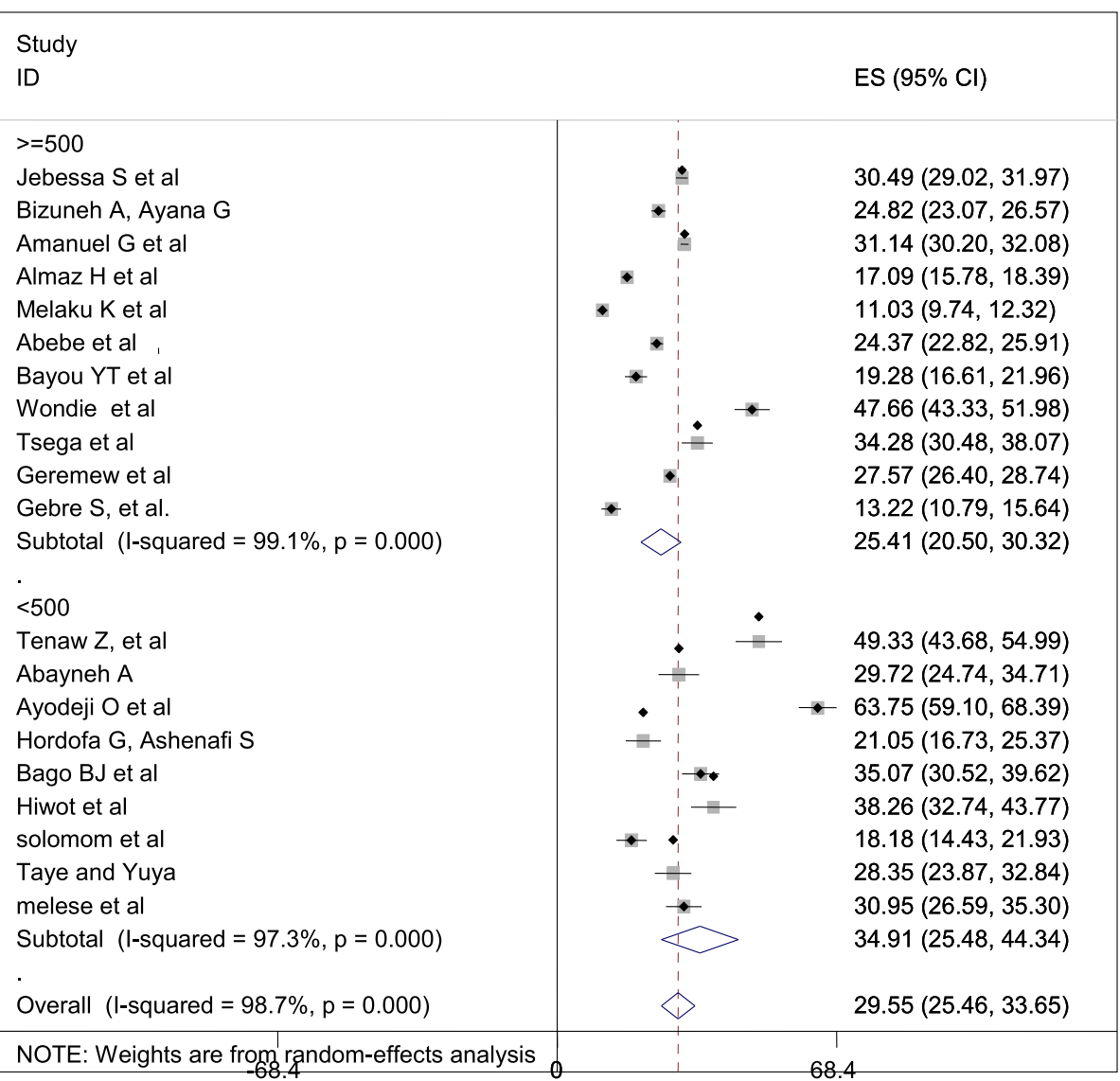

Fig. 4 Forest plot of the subgroup analysis based on region (area) of the study

\section{Prevalence of caesarean section in Ethiopia}

The overall pooled prevalence of Caesarean section is presented with a forest plot (Fig. 2). Therefore, the pooled estimated prevalence of Caesarean section in Ethiopia was $29.55 \%$ (95\% CI; 25.46-33.65; I2 $=98.7 \%$, $P<0.001)$.

\section{Publication bias}

A funnel plot was assessed for the asymmetry distribution of the Caesarean section using visual inspection of the forest plot (Fig. 3). Egger's regression test showed with a $p$-value of 0.251 indicated the absence of publication bias.

\section{Subgroup analysis}

Subgroup analysis was computed with the evidence of heterogeneity. Hence the Cochrane $\mathrm{I}^{2}$ statistic $=98.7 \%, P<$ 0.001 ) showed the presence of marked heterogeneity in this study. Therefore subgroup analysis was implemented using the study area (region) and sample size using random model effect analysis. Regarding the study area (region), the prevalence of Caesarean section was highest in Addis Ababa, accounted for 40.39\% (95\%CI: 12.35, 68.43) whereas the rate of Caesarean section was higher among studies of having sample size less than 500, accounted for 34.91\% (95\%CI: 25.48-44.34) (Fig. 4-5).

\section{Indication of caesarean section}

In this systematic review and meta-analysis; obstructed labor, cephalopelvic disproportion, multiple pregnancies, non-reassuring fetal heart rate pattern (NRFHRP), failed induction and augmentation, malpresentation and malposition, and antepartum hemorrhage are the most common indications of Caesarean section. In this systematic review and meta-analysis, cephalopelvic disproportion (CPD) is the most common indication of Caesarean section followed by non-reassuring fetal heart rate pattern (NRFHRP), and obstructed labor in Ethiopia (Table 2).

\section{Neonatal complication following caesarean section in Ethiopia}

Among women who underwent Caesarean section; neonatal sepsis, early neonatal death, stillbirth, low Apgar score, perinatal asphyxia (PNA), meconium aspiration syndrome, and prematurity were the reported neonatal complications in this study. Among neonatal complications, low 


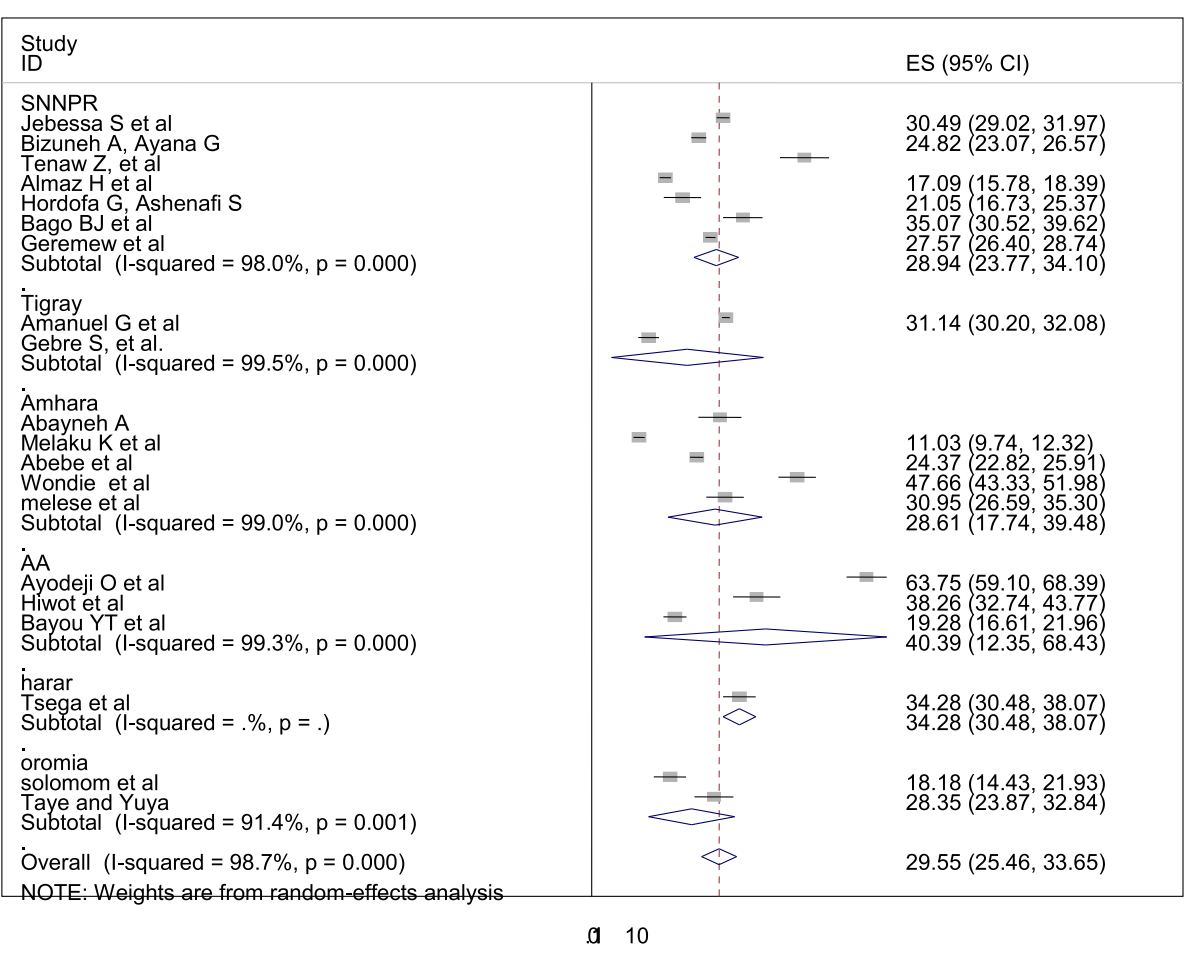

Fig. 5 Forest plot of the subgroup analysis based on the sample size of the study

Apgar score was the most common adverse complication of the newborn followed by perinatal asphyxia and neonatal sepsis respectively in Ethiopia (Table 3).

\section{Maternal complications following caesarean section in Ethiopia}

Following Caesarean section different adverse maternal complications were reported. Febrile morbidity, puerperal sepsis, postpartum hemorrhage, surgical site infection, maternal mortality, and severe anemia were the most common adverse maternal complications following Caesarean section. Puerperal fever or febrile morbidity was the leading cause of maternal morbidity following
Caesarean section followed by postpartum hemorrhage in Ethiopia (Table 4).

\section{Discussion}

Despite Caesarean section is an essential component of comprehensive obstetric and newborn care for reducing maternal and neonatal mortality, there is a lack of data regarding Caesarean section rates, its indications and outcomes in Ethiopia. Studies showed negative or no complications of Caesarean on neonatal mortality in low and middle-income countries where the Caesarean rates are high. Cesarean section is very crucial in settings where the Caesarean rates are very low, due to the unavailability of Caesarean [39].

Table $\mathbf{2}$ Indications of Caesarean section in Ethiopia

\begin{tabular}{|c|c|c|c|c|c|}
\hline Indications of Caesarean section & Model & Status of heterogeneity & Prevalence $(95 \% \mathrm{Cl})$ & $1^{2}(\%)$ & $P$-value \\
\hline Cephalopelvic disproportion & Random & Marked heterogeneity & $18.13(12.72-23.53)$ & 99.1 & $\leq 0.001$ \\
\hline Obstructed labor & Random & Marked heterogeneity & $15.25(5.21-25.3)$ & 99.8 & $\leq 0.001$ \\
\hline Failed induction/Augmentation & Random & Marked heterogeneity & $6.38(4.53-8.23 .3)$ & 98.1 & $\leq 0.001$ \\
\hline Non-reassuring fetal heart rate pattern (NRFHRP) & Random & Marked heterogeneity & 19.57(16.06-23.08) & 90.4 & $\leq 0.001$ \\
\hline Antepartum hemorrhage & Random & Marked heterogeneity & $7.59(6.1-9.08)$ & 95.7 & $\leq 0.001$ \\
\hline Malpresentation and malposition & Random & Marked heterogeneity & $9.74(7.08-12.41)$ & 98.6 & $\leq 0.001$ \\
\hline Having more than one pregnancy (multiple gestations) & Random & Marked heterogeneity & $5.17(4.08-6.25)$ & 91.7 & $\leq 0.001$ \\
\hline
\end{tabular}


Table 3 Neonatal complications following Caesarean section in Ethiopia

\begin{tabular}{|c|c|c|c|c|c|}
\hline$\underline{\text { Neonatal complications }}$ & Model & Status of heterogeneity & Prevalence $(95 \% \mathrm{Cl})$ & $I^{2}(\%)$ & $P$-value \\
\hline Prematurity & Random & Marked heterogeneity & $8.26(2.81-13.7)$ & 99.8 & $\leq 0.001$ \\
\hline Low APGAR score & Random & Marked heterogeneity & $22.21(13.57-30.85)$ & 98.6 & $\leq 0.001$ \\
\hline Meconium aspiration syndrome (MAS) & Random & Marked heterogeneity & 10.47(3.61-17.33) & 98.8 & $\leq 0.001$ \\
\hline Perinatal asphyxia (PNA) & Random & Marked heterogeneity & $19.91(7.52-32.2)$ & 99.9 & $\leq 0.001$ \\
\hline Neonatal sepsis & Random & Marked heterogeneity & 19.15(1.78-36.51) & 99.9 & $\leq 0.001$ \\
\hline Early neonatal death (END) & Random & Marked heterogeneity & $2.19(0.98-3.37)$ & 97 & $\leq 0.001$ \\
\hline Stillbirth & Random & Marked heterogeneity & $5(3.11-6.89)$ & 97 & $\leq 0.001$ \\
\hline
\end{tabular}

Caesarean sections can cause significant and sometimes permanent complications, disability or death particularly in settings that lack the facilities and/or capacity to properly conduct safe surgery and treat surgical complications [40].

Low- and middle-income countries, wealthy women have more than five times higher $\mathrm{C}$-section use than poor women. In the United States, 32\% of births were by C-section in 2015, an increase from $23 \%$ in 2000 , as the data showed, and in the United Kingdom, 26.2\% of births were by C-section in 2015, up from $19.7 \%$ in 2000. According to the World Health Organization report, the country with the lowest C-section rate, at $0.6 \%$ in 2010, was South Sudan and the country with the highest, at 58.1\% in 2014, was the Dominican Republic. Whereas, some countries where more than half of births were by C-section were Brazil, at 55.5\% in 2015; Egypt, at $55.5 \%$ in 2014; Turkey, at $53.1 \%$ in 2015 ; and Venezuela, at $52.4 \%$ in 2013 [41].

The overall prevalence of Caesarean section in Ethiopia was $29.55 \%$ (95\% CI: $25.46-33.65$ ). This report is higher than the study done in Saudi Arabia [42], Nigeria [43], Pakistan [44], India [5], Brazil [45] and low and middleincome countries analysis [46]. This discrepancy might be due to the age of the mother elapses the ideal birth time, significantly increasing, non-communicable disease, increasing electronic fetal monitoring availability and accessibility in referral and general hospitals. This study finding is lower than the study done in Nepal, North America and Western Europe, Latin America and the Caribbean [47]. This difference might be due to countries with a rich wealth index that may have the capacity to have modern operative obstetrics management as compared to low and middle countries. Hence, low and middle-income countries have resource limitation and c-section is resourceconstrained, may have low comprehensive obstetric health care services.

Antepartum hemorrhage, non-reassuring fetal heart rate pattern, malpresentation, and malposition, failed induction, obstructed labor, multiple gestations, cephalopelvic disproportion were the most common indications of Caesarean section in Ethiopia. This study finding is supported by the study done in low and middle-income countries [46], Saudi Arabia [42], Ghana [6, 8], Jordan [4] and India [5].

Neonatal sepsis, stillbirth, prematurity, perinatal asphyxia, low Apgar score, and meconium aspiration syndrome were the most common neonatal complications following the Caesarean section in Ethiopia. This study finding is supported by the study done in India [5], Jordan [4], and Ghana [6].

Postpartum hemorrhage, surgical site infection, puerperal fever, anemia, and maternal mortality were the most common neonatal adverse outcome of Caesarean section in Ethiopia. The finding of this study is supported by the study done in India [5], Jordan [4], and African countries [48].

\section{Conclusion}

In this study, the overall pooled prevalence of Caesarean section in Ethiopia was high. Non-reassuring fetal heart rate patterns, cephalopelvic disproportion, and obstructed labor were the most common indication of Caesarean section. Low Apgar score, perinatal asphyxia,

Table 4 Maternal complications following Caesarean section in Ethiopia

\begin{tabular}{|c|c|c|c|c|c|}
\hline Maternal complications & Model & Status of heterogeneity & Prevalence $(95 \% \mathrm{Cl})$ & $1^{2}(\%)$ & $P$-value \\
\hline Maternal mortality & Random & Marked heterogeneity & $0.66(0.14-1.17)$ & 81.4 & $\leq 0.001$ \\
\hline Severe anemia & Random & Marked heterogeneity & $2.06(0.04-4.09)$ & 80.6 & $\leq 0.001$ \\
\hline Puerperal fever or febrile morbidity & Random & Marked heterogeneity & $16.44(10-22.87)$ & 99.9 & $\leq 0.001$ \\
\hline Surgical site infection & Random & Marked heterogeneity & $10.81(5.74-15.88)$ & 98.9 & $\leq 0.001$ \\
\hline Postpartum hemorrhage & Random & Marked heterogeneity & $13.25(8.34-18.15)$ & 99.3 & $\leq 0.001$ \\
\hline
\end{tabular}


and neonatal sepsis were the most common complication of neonates whereas postpartum hemorrhage and febrile morbidity were the common maternal complications following the Caesarean section in Ethiopia. Therefore, based on the study findings, the authors recommend a particular emphasis to follow the WHO recommendations and guidelines. Avoiding unjustified and unnecessary indications for Caesarean sections has a significantly higher impact to prevent poor maternal and fetal outcomes.

\section{Abbreviations}

CS: Caesarean section; PPH: Postpartum hemorrhage; OL: Obstructed labor; CPD: Cephalopelvic disproportion; APH: Antepartum hemorrhage; SNNPR: South Nation Nationalities and Peoples region; Cl: Confidence Interval; OR: Odd Ratio

\section{Acknowledgments}

Not applicable.

\section{Authors' contributions}

All authors (GG,AD, BA, AW, AG \& FW, critically reviewed, provided substantive feedback and contributed to the intellectual content of this paper and made substantial contributions to the conception, conceptualization and manuscript preparation of this systematic review. All authors read and approved the final manuscript.

\section{Funding}

Not applicable.

\section{Availability of data and materials}

All related data has been presented within the manuscript. The dataset supporting the conclusions of this article is available from the corresponding author on request.

\section{Ethics approval and consent to participate}

Not applicable.

\section{Consent for publication}

Not applicable.

\section{Competing interests}

The authors declared that they have no competing interests.

\section{Author details}

'Department of Midwifery, College of Health Sciences, Woldia University, P.O.Box:400, Woldia, Ethiopia. ${ }^{2}$ Department of Nursing, College of Health Sciences, Woldia University, P.O.Box:400, Woldia, Ethiopia. ${ }^{3}$ Department of Medical Laboratory Sciences, College of Health Sciences, Woldia University, P.O.Box:400, Woldia, Ethiopia. ${ }^{4}$ Department of Midwifery, College of Medicine and Health Sciences, Bahir Dar University, Bahir Dar, Ethiopia.

Received: 22 November 2019 Accepted: 30 March 2020

Published online: 07 April 2020

\section{References}

1. Lyell DJ, Power M, Murtough K, Ness A, Anderson B, Erickson K, Schulkin J. Surgical techniques at cesarean delivery: a US survey. Surg J. 2016;2(04): e119-25.

2. Strom S. Rates, Trends, and Determinants of Cesarean Section Deliveries in El Salvador: 1998 to 2008 (doctoral dissertation); 2013.

3. Rayburn WF, Strunk AL. Profiles about practice settings of American College of Obstetricians and Gynecologists fellows. Obstet Gynecol. 2013;122(6): 1295-8.

4. BĂӨĞŚ̆ AM, Al-Daradkah SA, Khader YS, Basha A, Sabet F, et al. Cesarean

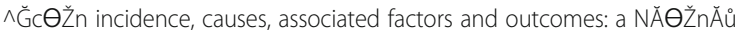
WrŽĖĞcӨlĞ study from Jordan. Gynecol Obstet Case Rep. 2017;3(3):5.
5. Desai G, Anand A, Modi D, Shah S, Shah K, Shah A, et al. Rates, indications, and outcomes of caesarean section deliveries: a comparison of tribal and non-tribal women in Gujarat, India. PLoS One. 2017;12(12):e0189260. https:// doi.org/10.1371/journal.pone.0189260.

6. Gulati D, Hjelde Gl. Indications for Cesarean Sections at Korle Bu Teaching Hospital. Ghana (Master's thesis); 2012.

7. Betrán AP, Merialdi M, Lauer JA, Bing-Shun W, Thomas J, Van Look P, Wagner M. Rates of caesarean section: analysis of global, regional and national estimates. Paediatr Perinat Epidemiol. 2007:21(2):98-113.

8. Faith $\mathrm{A}$, et al. Indication and predictors for caesarean sections in Ghana and the birth outcomes. Euro J Obstetrics Gynecology Reprod Biology. 2019;234:e1-e131.

9. Central Statistical Agency (CSA) [Ethiopia] and ICF. Ethiopia demographic and health survey 2016: Addis Ababa, Ethiopia, and Rockville, Maryland, USA: CSA and ICF; 2016. available at: https://dhsprogram.com/pubs/pdf/ FR328/FR328.pdf, accessed Mar 2020.

10. Bailey P, Lobis S, Maine D, Fortney JA. Monitoring emergency obstetric care: a handbook: World Health Organization; 2009..

11. Peters M, Godfrey C, Mclnerney P, Soares C, Hanan K, Parker D. The Joanna Briggs institute Reviewers' manual 2015: methodology for JBI scoping reviews; 2015.

12. Akki JS, Gemeda DH, Akessa GM. A review of caesarean delivery in Southwest Ethiopia: incidence, indications, and outcomes. Afr J Midwifery Womens Health. 2015;9(3):106-11.

13. Ayano B, Guto A. Indications and outcomes of emergency caesarean section at St Paul's hospital medical college, Addis Ababa, Ethiopia 2017:(afoul month retrospective cohort study). Gynecol Reprod Health. 2018;2(5):1-12.

14. Egger M, Smith GD, Schneider M, Minder C. Bias in meta-analysis detected by a simple, graphical test. BMJ. 1997;315(7109):62934.

15. Ioannidis J. Interpretation of tests of heterogeneity and bias in metaanalysis. J Eval Clin Pract. 2008;14(5):951-7.

16. Higgins J, Thompson SG. Quantifying heterogeneity in a meta-analysis. Stat Med. 2002;21(11):1539-58.

17. Borenstein M, Hedges LV, Higgins JP, Rothstein HR. A basic introduction to fixed-effect and random-effects models for meta-analysis. Res Synth Methods. 2010;1(2):97-111

18. Tadesse H, Gessessew A, Medhanyie AA. Trends and outcomes of cesarean delivery in Ayder comprehensive specialized hospital, Mekelle City, northern Ethiopia. East Afr J Health Sci. 2019;1(1):62-77.

19. Tesfaye T, Hailu D, Mekonnen N, Tesfaye R. Magnitude of maternal complication and associated factors among mothers undergone cesarean section at Yirgalem general hospital, SNNPR, Ethiopia. Risk. 2017;100:11.

20. Tenaw Z, Kassa ZY, Kassahun G, Ayenew A. Maternal Preference, Mode of Delivery and Associated Factors among Women Who Gave Birth at Public and Private Hospitals in Hawassa City, Southern Ethiopia. Ann Global Health. 2019;85(1):1-7. 115. https://doi.org/10.5334/aogh.2578.

21. Solomon AA. Prevalence of Ceserean Section and Associated Factors in University of Gondar Comprehensive Referal Hospital, North West Ethiopia. BMC Res Notes Rev. 2019. https://doi.org/10.21203/rs.2.13345/v1.

22. Hailu A. Assessment of leading indication and outcome of cesarean delivery in Arba Minch general hospital- a Cross-Sectional Study (MSc dissertation, Arba Minch Universty); 2016

23. Olanipekun A. Prevalence of caesarean section and the associated factors in private hospitals in Addis Ababa-a cross-sectional study (Doctoral dissertation, Addis Abeba Universty); 2017.

24. Gutema H, Shimye A. Cesarean section and associated factors at mizan aman general hospital, Southwest Ethiopia. J Gynecol Obstet. 2014;2(3):37-41.

25. Yenit MK, Gezahegn T, Adefires M, Shiferaw AM. Cesarean section rate, maternal and fetal outcome of birth following cesarean section at Finoteselam hospital, Northwest Ethiopia: A Descriptive Retrospective Data. Glob J Med Res. 2016.

26. Bago BJ. Prevalence and its associated factors among women undergone operative delivery at Hawassa University comprehensive specialized hospital, southern Ethiopia, 2017. Gynecol Obstet. 2018;8:461. https://doi. org/10.4172/2161-0932.100046.

27. Abebe FE, et al. Factors leading to cesarean section delivery at Felegehiwot referral hospital, Northwest Ethiopia: a retrospective record review. Reprod Health. 2016;13:6. https://doi.org/10.1186/s12978-015-0114-8.

28. Tsegaye $\mathrm{H}$. Prevalence of caesarean section and associated factors in Addis Ababa hospitals, Addis Ababa, Ethiopia, 2017 (Doctoral dissertation, Addis Ababa University); 2017.

29. Getahun A. Outcome of cesarean section and the associated factors at jugel hospital, harari region, eastern Ethiopia. 2015(doctoral dissertation, Haramaya University); 2015 
30. Bayou YT, Mashalla YJ, Thupayagale-Tshweneagae G. Patterns of caesareansection delivery in Addis Ababa, Ethiopia. Afr J Primary Health Care Fam Med. 2016;8(2):1-6.

31. Wondie AG, Zeleke AA, Yenus H, Tessema GA. Cesarean delivery among women who gave birth in Dessie town hospitals, Northeast Ethiopia. PLoS One. 2019;14(5):e0216344.

32. Tsega F, Mengistie B, Dessie Y, Mengesha M. Prevalence of cesarean section in urban health facilities and associated factors in eastern Ethiopia: hospital based cross sectional study. J Preg Child Health. 2015;2(3):169-73.

33. Geremew A, et al. Prevalence and Outcome of Caesarean Section in Attat Hospital, Gurage Zone, SNNPR, Ethiopia. Arch Med. 2015;7(4):8.

34. Worku S. Rate and associated factors of caesarean section at chirozonal hospital,west harergae, oromia regional state, eastern Ethiopia. (MSC dissertation, Haramaya University); 2016.

35. Taye A, Yuya M. One year retrospective analysis of prevalence of caesarean section in Jimma University specialized hospital, South Western Ethiopia. J Preg Child Health. 2015;2:172. https://doi.org/10.4172/2376-127X.1000172.

36. Mengesha MB, et al. Maternal and fetal outcomes of cesarean delivery and factors associated with its unfavorable management outcomes; in Ayder Specialized Comprehensive Hospital, Mekelle, Tigray, Ethiopia. 2017 BMC Res Notes. 2019;12:650. https://doi.org/10.1186/s13104-019-4690-5.

37. Gebre S, Negasi A, Hailu A. Criteria based clinical audit of cesarean section in a general Hospital in West Tigray, Ethiopia. J Women's Health Care. 2017; 6:410. https://doi.org/10.4172/2167-0420.1000410.

38. Melese A. Magnitude of cesarean section delivery and its associated factors among mothers who gave birth at public hospitals in north wollo zone, northern Ethiopia. (Msc dissertation, Haramaya University); 2019.

39. Kyu HH, Shannon HS, Georgiades K, Boyle MH. Caesarean delivery and neonatal mortality rates in 46 low-and middle-income countries: a propensity-score matching and meta-analysis of demographic and health survey data. Int J Epidemiol. 2013;42(3):781-91.

40. Souza JP, Gulmezoglu A, Lumbiganon P, Laopaiboon M, Carroli G, Fawole B, et al. Caesarean section without medical indications is associated with an increased risk of adverse short-term maternal outcomes: the 2004-2008 WHO global survey on maternal and perinatal health. BMC Med. 2010;8:71.

41. Boerma T, Ronsmans C, Melesse DY, Barros AJ, Barros FC, Juan L, Moller AB, Say L, Hosseinpoor AR, Yi M, Neto DDLR. Global epidemiology of use of and disparities in caesarean sections. Lancet. 2018;392(10155):1341-8.

42. Zakai Ghadeer H, Alrowithi Abdullah S, Buhlaigah Afnan M, Alharbi Abdullah A, Hakami Abrar H, Alqahtani Hanoof A. Prevalence of caesarean section and its indicating factors among pregnant women attending delivery at king Abdulaziz University hospital, Jeddah city during 2016. EC Gynaecol. 2018;7(2):43-51.

43. Adewuyi EO, Auta A, Khanal V, et al. Cesarean delivery in Nigeria: prevalence and associated factors - a population-based crosssectional study. BMJ Open. 2019;9:e027273. https://doi.org/10.1136/ bmjopen-2018-027273.

44. Amjad A, Amjad U, Zakar R, Usman A, Zakar MZ, Fischer F. Factors associated with caesarean deliveries among child-bearing women in Pakistan: secondary analysis of data from the demographic and health survey, 2012-13. BMC Pregnancy Childbirth. 2018 Dec;18(1):113.

45. Almeida SD, Bettiol H, Barbieri MA, Silva AA, Ribeiro VS. Significant differences in cesarean section rates between a private and a public hospital in Brazil. Cadernos de saude publica. 2008;24:2909-18.

46. Ojo VA, Okwerekwu FO. A critical analysis of the rates and indications for caesarean section in a developing country. Asia-Oceania J Obstetrics Gynaecology. 1988 Jun;14(2):185-93.

47. C-section deliveries nearly doubled worldwide since 2000, study finds. https:// edition.cnn.com > c-section-rates-study-parenting-without-borders-intl.

48. Esterhuizen TM, et al. Maternal and neonatal outcomes after caesarean delivery in the African surgical outcomes study: a 7-day prospective observational cohort study. Lancet Glob Health. 2019;7:e513-22.

\section{Publisher's Note}

Springer Nature remains neutral with regard to jurisdictional claims in published maps and institutional affiliations.

Ready to submit your research? Choose BMC and benefit from:
- fast, convenient online submission
- thorough peer review by experienced researchers in your field
- rapid publication on acceptance
- support for research data, including large and complex data types
- gold Open Access which fosters wider collaboration and increased citations
- maximum visibility for your research: over 100M website views per year
At BMC, research is always in progress.
Learn more biomedcentral.com/submissions

